\title{
«Международная охрана интеллектуальной собственности»: правовое понятие и учебная дисциплина
}

\author{
Леанович Е. Б.*
}

В статье соотнесены современные тенденции международной охраны интеллектуальной собственности с задачами и методами преподавания одноименной учебной дисциплины. Автор дает понятие международной охраны интеллектуальной собственности в теоретическом и практическом плане. С учетом отечественной и зарубежной доктрины, права и практики в статье изложен тематический план и методология курса учебной дисциплины «Международная охрана интеллектуальной собственности». Особое внимание уделяется развитию коллизионного регулирования в области интеллектуальной собственности.

Ключевые слова: интеллектуальная собственность; территориальность интеллектуальной собственности; международная охрана интеллектуальной собственности; коллизионное регулирование интеллектуальной собственности.

Интеллектуальная собственность перемещается через национальные границы иначе, чем материальные объекты. Это связано с тем, что права на изобретение, произведение, товарный знак и другие объекты, относимые к этому широкому понятию, возникшие по законам одного государства, не обязательно признаются в другом государстве.

Национальные режимы и другие механизмы многочисленных международных соглашений во многом расширили возможность доступа иностранцев к национально-правовым системам охраны. Но до сих пор международный оборот интеллектуальной собственности довольно осложнен. По общему правилу правообладателю необходимо полагаться на требования законов того государства, где он испрашивает охрану. В результате может сложиться ситуация, когда в одном государстве есть правовая охрана интеллектуального достижения, а в другом нет. Независимо от того, есть патент или нет, изобретательская разработка так же реально существует повсеместно в мире, как и материальный предмет, созданный человеком в результате приложения * Леанович Елена Борисовна - к.ю.н., доцент кафедры международного частного и европейского права факультета международных отношений Белорусского государственного университета. leanovich@rambler.ru. 
физического труда. Но в правовом плане результат интеллектуальной деятельности не един, он распадается на правовые формы его охраны в разных государствах. В частности, патент, полученный в одном государстве, не дает оснований считать, что в других государствах у патентообладателя есть изобретения. Территориальные ограничения авторско-правовой охраны могут привести к тому, что охрана произведения по законам одного государства не исключает того, что по законам другого государства такого произведения не существует вовсе, поскольку оно подпадает под перечень неохраняемых. Эти и другие проявления принципа территориальности интеллектуальной собственности обостряют интерес к изучению правил охраны интеллектуальной собственности сразу в нескольких государствах.

В правовой литературе, а также в учебных планах высших учебных заведениях используются разные термины: «международно-правовая охрана интеллектуальной собственности», «международная защита интеллектуальной собственности», «интеллектуальная собственность в международном частном праве», «международная охрана интеллектуальной собственности» и ряд других. Они нередко употребляются как синонимы без уточнения сущностных различий между ними. Однако во всех случаях речь идет об одном явлении - специфике регламентации отношений интеллектуальной собственности с иностранным элементом. Цель настоящей статьи - выделить в ряду схожих терминов один из них, а именно - «международная охрана интеллектуальной собственности» и раскрыть его сущностное содержание. Во-первых, мы обоснуем предпочтение данного термина, во-вторых, раскроем методические основы отнесения к нему определенных вопросов.

Термин «международная охрана интеллектуальной собственности» устойчив. Он используется в специальной литературе не реже, чем другие термины в исследуемой области. В частности, из этого термина исходят в своих работах М.М. Богуславский ${ }^{1}$; Ю.Г. Матвеев ${ }^{2}$, А.М. Минков ${ }^{3}$, Е.И. Басалай ${ }^{4}$, О.Н. Толочко ${ }^{5}$

${ }^{1}$ Богуславский М.М. Участие СССР в международной охране авторского права / М.М. Богуславский. М.: «Юридическая литература», 1974. 104 с.

2 Матвеев Ю.Г. Международная охрана авторских прав. «Юридическая литература», 1987. 222 c.

${ }^{3}$ Минков А.М. Международная охрана интеллектуальной собственности. СПб: Изд. дом «Питер», 2001. 719 с.

${ }^{4}$ Басалай Е.И. Международная охрана интеллектуальной собственности: учебно-методическое пособие. Мн.: БИП-С плюс, 2006. 62 с.

5 Толочко О.Н. Международная охрана интеллектуальной собственности: пособие по одноименному спецкурсу для студентов специальности 1-24 01002 - Правоведение. 
Термин «международная охрана интеллектуальной собственности» является емким и конкретным. Он более правилен с семантической точки зрения, чем, скажем, «международно-правовая охрана интеллектуальной собственности», «международное право интеллектуальной собственности», «правовое регулирование интеллектуальной собственности в международном аспекте» и другие термины, уточняющие правовую сторону исследуемой проблематики. Так, по сравнению с термином «международной охрана интеллектуальной собственности» термин «международно-правовая охрана интеллектуальной собственности» представляется несколько тавтологическим. Определение понятия «интеллектуальная собственность», данное в ст. 2 (viii) Конвенции, учреждающей ВОИС, 1967 г., исходит из того, что интеллектуальная собственность - это права на различные объекты: произведения, изобретения, товарные знаки и т.п. Данная конвенция действует для 184 стран мира. В соответствии с конвенционным определением мировое признание получило представление об интеллектуальной собственности как о правовом явлении. В гражданском законодательстве Российской Федерации интеллектуальной собственности - это категория, существующая исключительно в праве. Согласно ст. 1225 Гражданского кодекса Российской Федерации к интеллектуальной собственности относятся результаты интеллектуальной деятельности и приравненные к ним средствами индивидуализации юридических лиц, товаров, работ, услуг и предприятий, которым предоставляется правовая охрана.

Если принять во внимание, что о существовании произведения, изобретения и других объектов интеллектуальной собственности можно говорить только если они соответствуют определенным критериям, установленным в законе, то вне правовой охраны интеллектуальной собственности вообще нет. Таким образом, вполне можно обойтись без специальных уточнений «правовая», «в праве», «правовое регулирование» и т.п.

Использование выражения «международно-правовая охрана интеллектуальной собственности» вместо «международная охрана интеллектуальной собственности» сужает круг исследуемых вопросов. Международно-правовая охрана подразумевает использование международно-правового метода регулирования отношений и отсылает к анализу международных договоров и других источников международного

Гродно: ГрГУ, 2008. $179 \mathrm{c.}$ 
публичного права. Раскрытие проблематики в плоскости международного частного права не позволяет ограничиться только международноправовым регулированием. Для того чтобы понять, как интеллектуальная собственность охраняется в нескольких государствах необходимо обратиться к источникам и методам правового регулирования международного частного права, в первую очередь к национальному праву, включая материальные, коллизионные и процессуальные нормы.

Поэтому в целях всестороннего исследования проблемы пересечения интеллектуальной собственностью национальных границ предлагаем понимать под международной охраной интеллектуальной собственности получение охраны и осуществление защиты прав интеллектуальной собственности в договорных и внедоговорных отношениях с иностранным элементом. За основу взято ключевое понятие предмета международного частного права - отношения с иностранным элементом. Такой подход кардинально отличается от предшествующих исследований, которые в основном сводятся к изложению норм международных соглашений по вопросам интеллектуальной собственности. Такой подход был характерен для советской правовой доктрины 6 и используется современными исследователями ${ }^{7}$.

Сведения о международных соглашениях не дают полного представления о том, как в действительности осуществляется распространение охраны интеллектуальной собственности за пределы одного государства, т.е. как складывается практика ее получение в разных странах мира. Для отношений интеллектуальной собственности с иностранным

${ }^{6}$ Богуславский М.М. Патентные вопросы в международных отношениях. М.: Изд-во АН СССР, 1962. 344 с.; Богуславский М.М. Вопросы авторского права в международных отношениях. М.: Наука, 1973. 336 с.; Богуславский М.М. Участие СССР в международной охране авторского права. М.: «Юридическая литература», 1974. 104 с.; Матвеев Ю.Г. Международные конвенции по авторскому праву. 2-е изд., перераб. и доп. М.: «Международные отношения», 1978. 176 с.; Шатров В.П. Международное сотрудничество в области изобретательского и авторского права. М.: «Международные отношения», 1982. 240 с.; Матвеев Ю.Г. Международная охрана авторских прав. М.: «Юридическая литература», 1987. 222 с.

77 Минков А.М. Международная охрана интеллектуальной собственности. СПб: Изд. дом «Питер», 2001. 719 с.; Сенкевич К.И. Международные соглашения в области охраны промышленной собственности : автореф. дис. канд. юрид. наук : 12.00.03; Росс. гос. инст. интеллект. собств. М., 2004. 29 с.; Басалай Е.И. Международная охрана интеллектуальной собственности: учебно-методическое пособие. Мн.: БИП-С плюс, 2006. 62 с.; Толочко О.Н. Международная охрана интеллектуальной собственности: пособие по одноименному спецкурсу для студентов специальности 1-24 01002 Правоведение. Гродно: ГрГУ, 2008. 179 с. 
элементом в гораздо большей степени, чем для любых других отношений, исследуемых в международном частном праве важен сравнительный анализ права иностранных государств. Значение и содержание правил международных соглашений в области интеллектуальной собственности осознать гораздо проще, обладая сведениями о различиях в национально-правовом регулировании интеллектуальной собственности, пусть даже самого общего порядка.

Многие авторы трудов по праву интеллектуальной собственности подчеркивают, что в современных условиях коммерциализации объектов интеллектуальной собственности в мировом масштабе практикующему юристу недостаточно знаний только национального права интеллектуальной собственности. В частности, П.Б. Мэггс и А.П. Сергеев в своей монографии «Интеллектуальная собственность» пишут об этом так: «Роль юриста, специализирующегося в интеллектуальной собственности, в известном смысле сходна с ролью, которую играют юристы, консультирующие в других вопросах, но вместе с тем, она имеет свои серьезные отличия. Как и другие юрисконсульты, специалисты по интеллектуальной собственности должны охранять права своих клиентов и помогать им избегать нарушений прав других правообладателей. Но в отличие от юрисконсультов по другим вопросам специалисты по интеллектуальной собственности ответственны за охрану прав в ином масштабе, т. е. практически по всему миру» ${ }^{8}$.

Кроме того, изучение международной охраны интеллектуальной собственности не должно ограничиваться нормами международного и национального права. Необходимо обратить внимание на специфику международных договоров о создании и передаче прав на объекты интеллектуальной собственности и проанализировать правила и последствия включения в текст договора определенных положений, закрепляющих действие механизмов международного частного права между сторонами, например о выборе применимого права и органа, компетентного рассматривать спор.

Выделение проблемы международной охраны интеллектуальной собственности обязательно должно включать обращение к правилам и порядку урегулирования споров. Принцип территориальности задает определенную специфику применения правил международной подсудности, международного коммерческого арбитража и других

${ }_{8}^{8}$ Мэггс П. Б. Интеллектуальная собственность / П. Б. Мэггс, А. П. Сергеев. М.: Юристь, 2000. C. 33. 
альтернативных средств, признания и исполнения иностранных судебных и арбитражных решений в области интеллектуальной собственности. Термин «международная охрана интеллектуальной собственности» в данном выше определении подразумевает также обращение пристального внимания на стратегию защиты интеллектуальной собственности правообладателем. В современном мире международная охрана интеллектуальной собственности должна осуществляться с учетом широкого круга приемов и методов, которые предлагает право и практика, и включать использование технических и таможенных мер защиты интеллектуальной собственности, систем коллективного управления, различных приемов саморегулирования, получивших широкое распространение в Интернет (примером является практика разрешения споров об использовании объектов интеллектуальной собственности в доменных именах).

Заключение и исполнение международных договоров о передаче прав на объекты интеллектуальной собственности, вложение интеллектуальной собственности в уставные фонды организаций с иностранными инвестициями, предъявление требований о возмещении ущерба, причиненного в результате нарушения прав интеллектуальной в иностранном государстве (или еще сложнее в виртуальной среде - в Интернет) требует осуществления сложной юридической работы. Международная охрана интеллектуальной собственности как область научно-правовых исследований и учебного процесса должна отражать изменения, которые в настоящее время претерпевают право и практика.

Международная охрана интеллектуальной собственности базируется на очень широком круге национальных и международных правовых актов. Отношения интеллектуальной собственности, связанные с несколькими государствами, всегда регулируются комплексно. Они не определяются только национальным правом или только международными соглашениями. Поэтому, приступая к изучению вопросов международной охраны интеллектуальной собственности необходимо знать гражданское право и международное частное право в том объеме, в котором они изучаются на юридических факультетах высших учебных заведений в соответствии с государственным образовательным стандартом. Требуются также знания по международному публичному праву, поскольку специфика прав интеллектуальной собственности позволяет расширять территориальные рамки их охраны, в основном, благодаря широкой системе международных соглашений 
и деятельности международных организаций по организации межгосударственного сотрудничества на основе этих соглашений. Причем, явления последнего времени ставят очень сложные вопросы на стыке внутригосударственного и международно-правового регулирования: создание судебной системы в рамках Европейской патентной организации, единая охрана товарных знаков, промышленных образцов и ряда других объектов интеллектуальной собственности на уровне ЕС.

Учебная дисциплина «Международная охрана интеллектуальной собственности» преподается либо как одна из тем особенной части международного частного права, либо как спецкурс на его основе. Однако основному вопросу международного частного права - коллизионному регулированию применительно к интеллектуальной собственности уделяется очень мало внимания, нередко этот вопрос опущен вовсе.

В учебной литературе по международному частному праву проблемы интеллектуальной собственности рассматриваются очень усеченно, поскольку коллизионных вопросов интеллектуальной собственности либо нет вообще, либо они излагаются слишком сжато. Очень распространен подход, когда территориальностью интеллектуальной собственности обосновывается принципиальная невозможность коллизионного регулирования в этой области. В частности, В.А. Канашевский пишет: «Общим для авторских, смежных и промышленных прав является то, что они носят строго территориальный характер, т е. признаются и защищаются только на территории того государства, где они впервые возникли - опубликованы, зарегистрированы. Территориальный характер действия таких прав исключает коллизионный вопрос» 9 .

Тема «Интеллектуальная собственность в международном частном праве» обычно раскрывается путем характеристики международных соглашений в области интеллектуальной собственности ${ }^{10}$. Есть учебные издания, в которых проблемы интеллектуальной собственности в рамках международного частного права с точки зрения коллизионного регулирования все же излагаются, но они не сопровождаются объяснением тех результатов, к которым может привести применение

${ }^{9}$ Канашевский В.А. Международное частное право. М.: Международные отношения, 2006. 458-460.

${ }^{10}$ Ануфриева Л.П. Международное частное право: в 3-х т. Том 2. Особенная часть: учебник. 2-е изд., перераб. и доп. М.: Издательство БЕК, 2002. 656 с.; Международное частное право: учебник / Л.П. Ануфриева, К.А. Бекяшев, Г.К. Дмитриева и др.; Отв. ред. Г.К. Дмитриева. 2-е изд., перераб. и доп. М.: ТК Велби, Изд-во Проспект, 2004. 644 с. 
различных коллизионных привязок. Так, в учебнике В.Г. Тихини информация о международных соглашениях по вопросам интеллектуальной собственности предваряется фразой: «К правам на интеллектуальную собственность применяется право страны, где испрашивается защита этих прав» без указания на то как понимать такую отсылку и какие негативные или позитивные аспекты она в себе таит ${ }^{11}$. Есть учебники, в которых более подробно освещаются проблемы интеллектуальной собственности в международном частном праве. В частности, принцип территориальности и различные приемы коллизионного регулирования интеллектуальной собственности затронули в своих работах И.В. Гетьман-Павлова ${ }^{12}$ и М.М. Богуславский ${ }^{13}$. Однако современные тенденции в развитии проблемы интеллектуальной собственности в международном частном праве эти авторы не раскрывают. Между тем, коллизионное регулирование - это реалия современного мира, что подтверждается деятельностью ВОИС, ЕС, судебной практикой, научными исследованиями, нормативно-правовыми актами.

Международные соглашения по вопросам интеллектуальной собственности не устраняют необходимость применения национальных законов. Более того, отношения интеллектуальной собственности с иностранным элементом регулируются преимущественно национальными законами. В работах по международной охране интеллектуальной собственности национальное право исследуется исключительно с позиции того, соответствует ли право государства Х требованиям международных соглашений. Но практика международной охраны интеллектуальной собственности показывает, что даже самая широкая и успешная унификация не исключает коллизию, т.е. несовпадение национальных законов. Соответственно обозначается классическая задача международного частного права - решить коллизионный вопрос. Применить классические механизмы международного частного права к интеллектуальной собственности довольно сложно, но порой другого выхода нет. Наиболее простые примеры - международные договоры по вопросам

11 Тихиня В.Г. Международное частное право. 5-е изд. перераб. и доп. Мн.: Право и экономика, 2003. С. 205.

${ }^{12}$ Гетьман-Павлова И.В. Международное частное право: учебник / И.В. Гетьман-Павлова. М.: Изд-во Эксмо, 2005. 752 с. С. 314, 326.

13 Богуславский М.М. Международное частное право: учебник. 5-ое изд., перераб. и доп. М.: Юристъ, 2004. с. 357-359; Богуславский М.М. Международное частное право: учебник. 6-ое изд., перераб. и доп. М.: Издательство Норма ИНФРА-М, 2010. C. 413,416 . 
интеллектуальной собственности с иностранным элементом и нарушения прав интеллектуальной собственности в Интернет.

Содержание учебного курса по дисциплине «Международная охрана интеллектуальной собственности» представляется следующим:

- специфика интеллектуальной собственности и ее регламентации в международном частном праве (территориальность интеллектуальной собственности, иностранный элемент в отношениях интеллектуальной собственности, коллизионное регулирование интеллектуальной собственности),

- национальное право интеллектуальной собственности (история развития права интеллектуальной собственности, теоретико-философские концепции регулирования интеллектуальной собственности, общая характеристика охраны произведений, изобретений, товарных знаков в англо-американском, континентальном праве и в странах, входивших ранее в состав СССР),

- система международного сотрудничества в области интеллектуальной собственности (основные международные организации и соглашения, участие в них страны, охрана прав интеллектуальной собственности иностранцев, право интеллектуальной собственности ЕС),

- защита прав интеллектуальной собственности в международном обороте (приемы и средства защиты интеллектуальной собственности, разрешение споров, договорная практика - международные лицензионные и другие договоры по вопросам интеллектуальной собственности).

В современных условиях глобализации мир становится все более взаимосвязанным. Международная либерализация торговли, региональная экономическая интеграция, информационные технологии и Интернет требуют более согласованного взаимодействия правовых систем государств. Развитие национального и международного права подготовило необходимый базис для использования новых приемов в международной охране интеллектуальной собственности. В XXI в. и право интеллектуальной собственности, и международное частное право находятся на совершенно ином уровне развития, чем в конце XIX в. на момент принятия базовых конвенций по интеллектуальной собственности (Парижской конвенции по охране промышленной собственности 1883 г., Бернской конвенции об охране литературной и художественной собственности 1886 г. и др.) или в середине 70-ых гг. ХХ в., когда стали бурно развиваться процедуры международного патентования на универсальном и региональном уровнях (Договор о патентной 
кооперации, региональные патентные конвенции, значительный рост количества международных регистраций по процедурам Мадридского соглашения о международной регистрации знаков 1891 г.)

Основные проблемы современности в области международной охраны интеллектуальной собственности связаны с пересмотром традиционных представлений о территориальности интеллектуальной собственности. В рамках учебной дисциплины «Международная охрана интеллектуальной собственности» должны шире освещаться механизмы международного частного права применительно к интеллектуальной собственности: коллизионное регулирование и вопросы юрисдикции.

Отношения интеллектуальной собственности, которые складываются на международном уровне, т.е. тем или иным связаны с двумя и более государствами, являются предметом сложного, многосоставного по методам и составу источников правового регулирования. Коллизионное регулирование интеллектуальной собственности еще только начинает складываться и не имеет четкой нормативно-правовой регламентации. Вместе с тем, очень важно, чтобы студенты-юристы получали знания о возможности выбора применимого права в международных лицензионных соглашениях, об арбитрабельности международных споров по вопросам интеллектуальной собственности, о действии оговорки о публичном порядке, устраняющей действие иностранного права интеллектуальной собственности, а также по другим вопросам международного частного права, которые в настоящее время в недостаточной степени затронуты в литературе по международной охране интеллектуальной собственности. В частности, на занятиях по учебной дисциплине «Международная охрана интеллектуальной собственности» необходимо разбирать действующие и планируемые нормы международного частного права об интеллектуальной собственности. Студенты обязательно должны быть ознакомлены с «Принципами коллизионного регулирования в интеллектуальной собственности», которые являются рекомендательным документом, разработанным группой ведущих юристов из Германии, Великобритании, США, занимающихся вопросами интеллектуальной собственности в международном частном праве European Max-Planck Group on Conflict of Laws in Intellectual Property (CLIP), в котором изложены подробные коллизионные и юрисдикционные правила в области интеллектуальной собственности ${ }^{14}$. Необходимо

${ }^{14}$ Principles for conflict of laws in intellectual property. Second preliminary draft. June 6, 2009 [Electronic resource] / CLIP. Mode of access : http://www.ip.mpg.de/shared/data/pdf/ 
также подробно разбирать примеры из судебной и арбитражной практики, иллюстрирующие применение механизмов международного частного права к отношениям интеллектуальной собственности.

Теоретические и практические аспекты в международной охране интеллектуальной собственности тесно переплетены. Представляется чрезвычайно важным расширить знания правоведов в обоих направлениях. Интеллектуальная собственность не только предполагает охрану творческих достижений, от юриста, действующего в этой области, требуется определенная творческая работа по поиску оптимальной стратегии международной охраны интеллектуальной собственности, особенно в случае отсутствия или неполной правовой регламентации в праве.

\section{Библиографический список}

Ануфриева Л.П. Международное частное право: в 3-х т. Том 2. Особенная часть: учебник. 2-е изд., перераб. и доп. М.: Издательство БЕК, 2002. 656 с.

Басалай Е.И. Международная охрана интеллектуальной собственности: учебно-методическое пособие. Мн.: БИП-С плюс, 2006. 62 с.

Богуславский М.М. Вопросы авторского права в международных отношениях. М.: Наука, 1973. 336 с.

Богуславский М.М. Международное частное право: учебник. 5-ое изд., перераб. и доп. М.: Юристъ, 2004. 602 с.

Богуславский М.М. Международное частное право: учебник. 6-ое изд., перераб. и доп. М.: Издательство Норма ИНФРА-М, 2010. $704 \mathrm{c}$.

Богуславский М.М. Патентные вопросы в международных отношениях. М.: Изд-во АН СССР, 1962. 344 с.

Богуславский М.М. Участие СССР в международной охране авторского права. М.: «Юридическая литература», 1974. 104 с.

Гетьман-Павлова И.В. Международное частное право: учебник. М.: Изд-во Эксмо, 2005. 752 с.

Канашевский В.А. Международное частное право. М.: Международные отношения, 2006. 698 с.

Матвеев Ю.Г. Международные конвенции по авторскому праву. 2-е изд., перераб. и доп. М.: «Международные отношения», 1978. 176 с.

Матвеев, Ю.Г. Международная охрана авторских прав. М.: «Юридическая литература», 1987. 222 с.

draft-clip-principles-06-06-2009.pdf. Date of access : 5.06.2010. 
Международное частное право: учебник / Л.П. Ануфриева, К.А. Бекяшев, Г.К. Дмитриева и др.; Отв. ред. Г.К. Дмитриева. 2-е изд., перераб. и доп. М.: ТК Велби, Изд-во Проспект, 2004. 644 с.

Минков А.М. Международная охрана интеллектуальной собственности. СПб: Изд. дом «Питер», 2001. 719 с.

Мэггс П. Б. Интеллектуальная собственность / П.Б. Мэггс, А.П. Сергеев. М.: Юристъ, 2000. 396 с.

Сенкевич К.И. Международные соглашения в области охраны промышленной собственности : автореф. дис. канд. юрид. наук : 12.00.03; Росс. гос. инст. интеллект. собств. М., 2004. 29 с.

Тихиня В.Г. Международное частное право. 5-е изд. перераб. и доп. Мн.: Право и экономика, 2003. 408 с.

Толочко О. Н. Международная охрана интеллектуальной собственности: пособие по одноименному спецкурсу для студентов специальности 1-24 01002 - Правоведение. Гродно: ГрГУ, 2008. 179 с.

Шатров В.П. Международное сотрудничество в области изобретательского и авторского права / В.П. Шатров. М.: «Международные отношения», 1982. $240 \mathrm{c}$.

Principles for conflict of laws in intellectual property. Second preliminary draft. June 6, 2009 [Electronic resource] / CLIP. Mode of access: http:// www.ip.mpg.de/shared/data/pdf/draft-clip-principles-06-06-2009.pdf. Date of access: 5.06.2010. 


\section{To the Concept of "International Protection of Intellectual Property" in Educational Process \\ (Summary)}

\section{Elena B. Leanovich*}

The article correlates the current trends of international protection of intellectual property with objectives and methods of teaching in this field. The author gives the notion of international protection of intellectual property from the theoretical and practical points of view. Tacking into account domestic and foreign doctrine, law and practice the article sets out thematic plan and methodology of the academic discipline "International protection of intellectual property". Particular attention is given to the development of conflict of laws in the field of intellectual property.

Keywords: intellectual property; territoriality of intellectual property; international protection of intellectual property; conflict of laws regulating intellectual property.

\footnotetext{
* Elena B. Leanovich - Ph.D. in Law, assistant professor of the Chair of International Private and European law of the faculty of International Relations, Belarusian State University. leanovich@rambler.ru.
} 